\title{
High LARGEI Expression May Predict Benefit from Adjuvant Chemotherapy in Resected Non-Small-Cell Lung Cancer
}

This article was published in the following Dove Press journal: Pharmacogenomics and Personalized Medicine

\author{
Yu Liu' \\ Shirui Huang ${ }^{2}$ \\ Mengjiao Kuang ${ }^{2}$ \\ Huiyan Wang ${ }^{2}$ \\ Qipeng $X_{i e}{ }^{2}$ \\ 'Department of Cardiothoracic Surgery, \\ The First Affiliated Hospital of Wenzhou \\ Medical University, Wenzhou, Zhejiang \\ 325035, People's Republic of China; \\ ${ }^{2}$ Department of Laboratory Medicine, \\ The Second Affiliated Hospital and Yuying \\ Children's Hospital of Wenzhou Medical \\ University, Wenzhou, Zhejiang 325027, \\ People's Republic of China
}

Background: LARGE1 plays a pivotal role in glycosylation of alpha-Dystroglycan $(\alpha-D G)$ and is aberrantly downregulated in cell lines originating from epithelium-derived cancers including lung cancer. However, the expression of LARGE1 and its clinical significance in NSCLC are not clear.

Materials and Methods: The data were collected from the TCGA database to investigate LARGE1 expression in stage I-III NSCLC and explore its associations with clinicopathological parameters and overall survival of patients. The prognostic role of LARGE1 was examined in subgroups according to clinical features and treatments. The results were validated in external cohorts from the NCBI GEO database. Gene Set Enrichment Analysis (GSEA) was performed to investigate the potential molecular mechanisms during LARGE1 alteration in NSCLC.

Results: LARGE1 was aberrantly downregulated in NSCLC compared with adjacent tissues and normal lung tissues and in tumors with advanced stage compared with early stage. There was only a trend of association between high LARGE1 with OS in multivariate analysis. Surprisingly, high LARGE1 was significantly associated with improved OS in a subgroup of the patients with adjuvant chemotherapy (ACT) and a significant interaction between LARGE1 expression and ACT was found. Improved OS after ACT was also found in patients with high LARGE1 compared to those with low LARGE1. When combining LARGE1 expression and ACT, compared with patients with non-ACT, HR of low LARGE1/ACT was $0.592(95 \% \mathrm{CI}=0.432-0.813, P=0.0012)$, and HR of high LARGE1/ACT was 0.124 (95\% CI $=0.031-0.505, P=0.0036)$. The results were verified in two external cohorts from the GEO database. GSEA indicated that LARGE1 might downregulate cell cycle pathway to improve ACT sensitivity and subsequently the prognosis in NSCLC.

Conclusion: High LARGE1 can be used to identify the patients with resected stage I-III NSCLC most likely to benefit from adjuvant chemotherapy.

Keywords: NSCLC, LARGE1, mRNA, overall survival, adjuvant chemotherapy, benefit

\section{Introduction}

Lung cancer is one of the most common malignant tumors and the leading cause of cancer-related deaths worldwide. ${ }^{1}$ In 2020 , it is expected that there will be 228,820 cases of lung cancer and 135,720 related deaths in the United States. ${ }^{1}$ There are two main histological types of lung cancer: small cell lung cancer and non-small cell lung cancer (NSCLC). ${ }^{2}$ NSCLC accounts for approximately $85 \%$ of lung cancer cases and can further be divided into lung adenocarcinoma (LUAD) and lung
Correspondence: Qipeng Xie Department of Laboratory Medicine, The Second Affiliated Hospital and Yuying Children's Hospital of Wenzhou Medical University, Wenzhou, Zhejiang 325027,

People's Republic of China

Tel +86-15I57787I59

Email pandon2002@163.com 
squamous cell carcinoma (LUSC). ${ }^{2}$ The 5 -year survival rate of all patients with lung cancer is only about $19 \%$. ${ }^{1,3}$

Surgical resection is the main and most effective choice for NSCLC patients, but only $20 \%$ of patients are suitable for surgery due to late diagnosis ${ }^{4}$ and postoperative tumor recurrence is the major cause of treatment failure. ${ }^{5-7}$ Platinum-based adjuvant chemotherapy is one of the main means to improve the overall survival (OS) of patients with NSCLC after surgical resection, especially for patients with advanced tumors ${ }^{8}$ after several previous randomized clinical trials demonstrated ACT is associated with statistically significant survival advantages in patients with completely resected NSCLC. ${ }^{9-13}$ However, a metaanalysis of these studies suggested that ACT only provides an absolute benefit of $5.4 \%$ in 5 -year $\operatorname{OS}^{14}$ due to primary and acquired drug resistance. ${ }^{15}$ And the remaining $85 \%-$ $95 \%$ of patients do not get benefit from ACT but suffer the ACT toxicity. Thus, it is critical to identify NSCLC patients who will not benefit from ACT.

$L A R G E 1$, encoding a bifunctional glycosyltransferase, participates in glycosylation of $\alpha$-DG by synthesizing and transferring the laminin-binding repeating units of $3 \mathrm{GlcA}-$ 1-3Xyl-1 onto $\alpha$-DG. ${ }^{16}$ LARGE1 downregulation has been found to underlie abnormal glycosylation of $\alpha$-DG in epithelium-derived cancer cells lines derived from breast, cervical, and lung cancers and exogenous expression of LARGE1 restores normal glycosylation and laminin binding of $\alpha$-DG, leading to enhanced cell adhesion and reduced cell migration in vitro. ${ }^{17}$ Exogenous expression of LARGE1 has also been found to restore $\alpha$-DG matriglycan and laminin binding in rhabdomyosarcoma. ${ }^{18}$

Currently, the clinical significance of LARGE1 in lung cancer is not clear. In the present study, we utilized the large dataset of NSCLC patients from TCGA database to investigate the expression of LARGE1 and its clinical significance and further validated the results in external cohorts. In addition, we preliminarily explored the potential molecular mechanisms related to LARGE1 in NSCLC carcinogenesis.

\section{Materials and Methods Expression of LARGEI mRNA Expression in NSCLC}

TCGA TARGET GTEx dataset, which contains gene expression data in tumor tissues, adjacent tissues, and normal lung tissues, was downloaded from Xenabrowser. net $^{19}$ and used to investigate LARGE1 mRNA expression in NSCLC tumor tissues, adjacent tissues, and normal lung tissues.

\section{Kaplan-Meier Plotter}

Kaplan-Meier plotter (KM plotter), ${ }^{20}$ a web-based tool, is capable of assessing the effect of $54 \mathrm{k}$ genes (mRNA, miRNA, protein) on survival in 21 cancer types with the data from the databases including GEO, EGA, and TCGA. This tool consisted of 2,437 lung cancer cases with gene profile (mRNA) data determined by microarray. Of the 2,437 lung cases, 1,927 cases had OS information. We used the tool to initially analyze the association of LARGE1 expression with OS in lung cancer with Auto select best cutoff value and the JetSet best probe set (215543_s_at) for LARGE1.

\section{Analysis of NSCLC Data from TCGA}

To further investigate the associations of LARGE1 mRNA levels with clinicopathological features and OS in NSCLC, RNA-Seq data and corresponding clinical data of the NSCLC patients were downloaded from TCGA database by Xenabrowser.net. ${ }^{19}$ The correlations between LARGE1 expression and baseline clinical characteristics in NSCLC patients were examined by the Chi-square test or Fisher's exact test as appropriate. Kaplan-Meier plot curves were used to explore the association of LARGE1 expression (optimal cutoff value) with OS in overall NSCLC patients. Univariate/multivariate Cox proportional hazards regression models were also used to explore the effects of LARGE1 mRNA levels on OS in overall and subgroups stratified by age, gender, smoking history, tumor stage, margin status, and adjuvant chemotherapy (ACT) treatment. Furthermore, LARGE1 expression and ACT were also combined to classify NSCLC patients to observe their OS difference in Kaplan-Meier curves and Cox proportional hazards regression models.

\section{Validation}

To validate the results from the TCGA cohort, external cohort studies were searched in NCBI GEO database. The datasets in which: 1) the subjects were resected NSCLC patients; (2) the patients were treated with adjuvant chemotherapy and without chemotherapy; and 3) contained follow-up information (OS time and status) and contained LARGE1 expression levels analyzed by microarray or high throughput sequencing were downloaded. Only TNM stage I-III patients were enrolled. The datasets GSE42127, ${ }^{21}$ 
GSE14814, ${ }^{22}$ and GSE68465 ${ }^{23}$ were included (Tables S1 and $\underline{\mathrm{S}}$ ).

\section{Gene Set Enrichment Analysis}

To investigate the potential molecular mechanisms during LARGE1 alteration in lung cancer, the Spearman correlations analysis results of more than 20,000 genes with LARGE1 in lung adenocarcinoma in the TCGA database were downloaded via cBioPortal (cbiopartal.org). ${ }^{24,25}$ The genes were ranked by the Spearman's rank $r$ and subjected to Gene Set Enrichment Analysis (GSEA) via software, JAVA GSEA 3.0 (http://software.broadinstitute.org/gsea/ index.jsp). ${ }^{26,27}$ The biologically defined gene sets "c2.cp. kegg.v7.1.symbols.gmt," "c7.all.v7.1.symbols.gmt," and "h. all.v7.1.symbols.gmt" were used as the reference databases.

\section{Association of LARGE mRNA Expression with Cell Cycle Pathway Score}

Akbani et al have used reverse phase protein array (RPPA) data from TCGA to calculate the score for 10 cancerrelated pathways in 32 cancer types including cell cycle pathway. ${ }^{28}$ RPPA is a high-throughput antibody-based technique with procedures similar to that of Western blots. The pathway score is then the sum of the relative protein level of all positive regulatory components minus that of negative regulatory components in a particular pathway. For the cell cycle pathway, its score is the sum of the relative protein levels of CDK1, CYCLINB1, CYCLIND1, CYCLINDE1, CYCLINE2, P27PT157, P27PT198, and PCNA. Association of LARGE1 expression with cell cycle pathway score in lung adenocarcinoma was analyzed by Spearman correlation analysis.

\section{Statistical Analysis}

Kruskal-Wallis tests were used to compare LARGE1 expression in NSCLC tumor tissues, adjacent tissues, and normal lung tissues and in patients with different stages. Fisher's exact test or Chi-square test were used to determine the associations of LARGE1 expression with clinical features of NSCLC patients. Kaplan-Meier curves and univariate Cox proportional hazards regression models as well as Kaplan-Meier curves adjusted by confounding factors and multivariate Cox proportional hazards regression models were used to clarify the effects of LARGE1 expression on OS in NSCLC patients. All statistical analyses were performed with $\mathrm{R}$ software (v 3.4.3). A twosided $P<0.05$ was considered statistically significant.

\section{Results}

LARGEI Was Downregulated in NSCLC TCGA TARGET GTEx dataset was used to investigate LARGE1 mRNA expression in NSCLC tumor tissues, adjacent tissues, and normal lung tissues. LARGE1 was found to be downregulated in LUAD tumor tissues (Figure 1A) and LUSC tumor tissues (Figure 1B) compared with corresponding adjacent tissues and normal lung tissues. In addition, LARGE1 expression was determined in tumors with different stages in patients with TNM I-III NSCLC. The results suggested that LARGE1 was decreasingly expressed along with advancing tumor T stage (Figure $1 \mathrm{C}$ and $\mathrm{D}$ ), N stage (Figure $1 \mathrm{E}$ and $\mathrm{F}$ ), and TNM stage (Figure $1 \mathrm{G}$ and $\mathrm{H}$ ) in both LUAD (Figure 1C, E, and G) and LUSC (Figure 1D, F, and H), especially in LUAD.

\section{Correlations of LARGEI Expression with Clinicopathological Features in Stage I-III NSCLC Patients}

A total of 981 NSCLC patients from the TCGA database with baseline clinical characteristics and OS outcome information were split into a high LARGE1 expression group and a low LARGE1 expression group by the median value of LARGE1 expression. As shown in Table 1, high LARGE1 was associated with advanced $\mathrm{T}$ stage, $\mathrm{N}$ stage, TNM stage, LUSC, and older age but not with gender and smoking history.

\section{Correlations of LARGEI Expression Levels with Overall Survival in Stage I-III NSCLC Patients}

Effects of LARGE1 expression levels on OS in NSCLC was first examined using Kaplan-Meier plotter (KM plotter) and high LARGE1 expression was found to be associated with favorable OS in 1,925 NSCLC patients (Figure 2A). Then the effect of LARGE1 expression on OS was investigated in the 981 NSCLC patients from TCGA. Increased LARGE1 expression was associated with favorable OS in NSCLC revealed by both Kaplan-Meier curve with Log rank test (optimal cutoff value, $P=0.028$; Figure $2 \mathrm{~B}$ ) and univariate Cox proportional hazards regression model ( $\mathrm{HR}=0.797 ; 95 \%$ $\mathrm{CI}=0.651-0.976 ; P=0.029)$. However, the association was not significant in the multivariate model $(\mathrm{HR}=0.806,95 \%$ $\mathrm{CI}=0.633-1.027, P=0.081)$. Next, we used LARGE1 expression level as a continuous variable to explore its effects on OS in different subgroups stratified by age, gender, smoking 
A

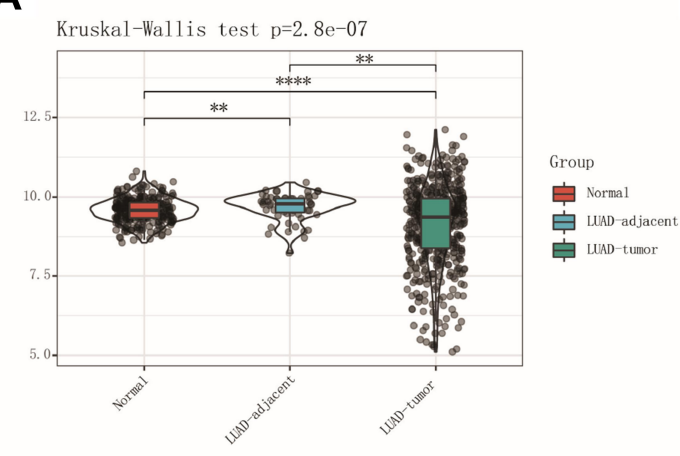

C

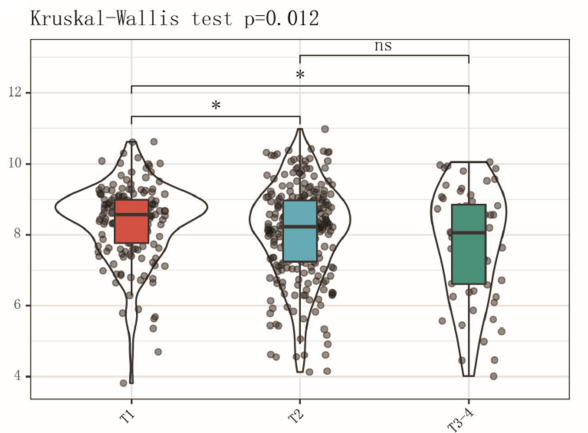

E

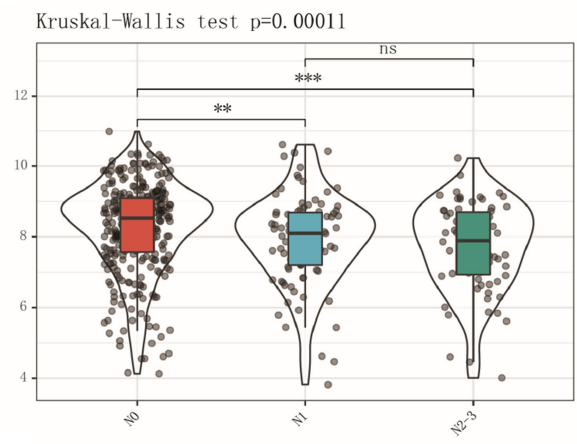

G

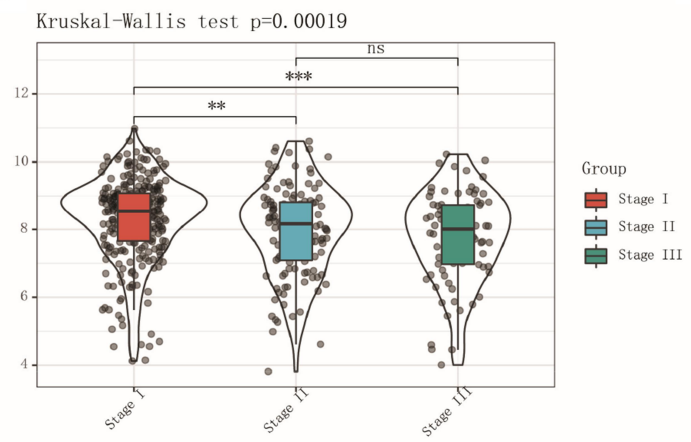

B

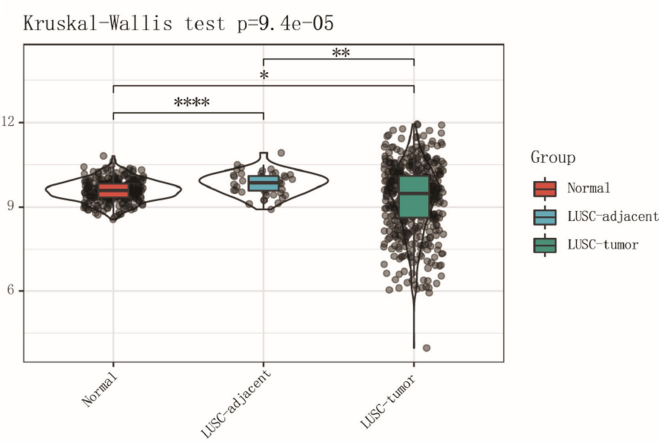

D

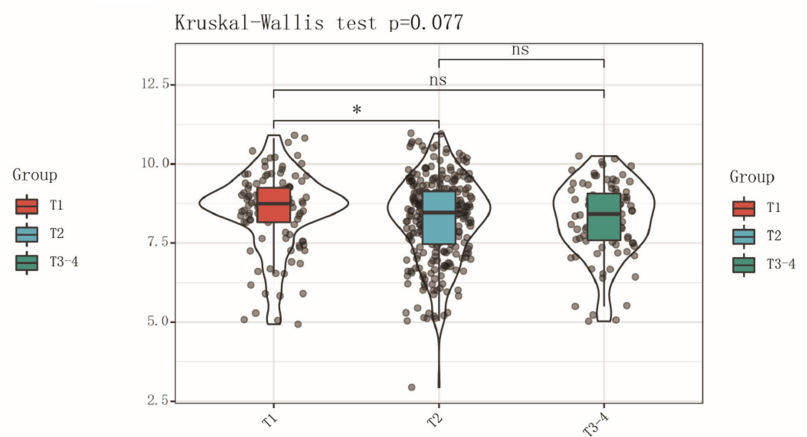

F

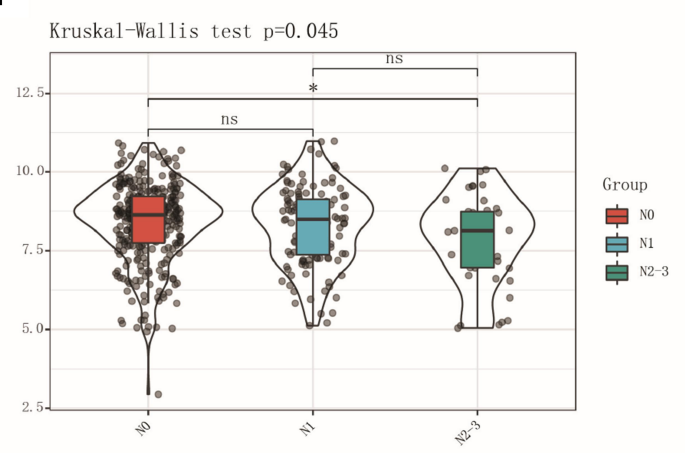

H

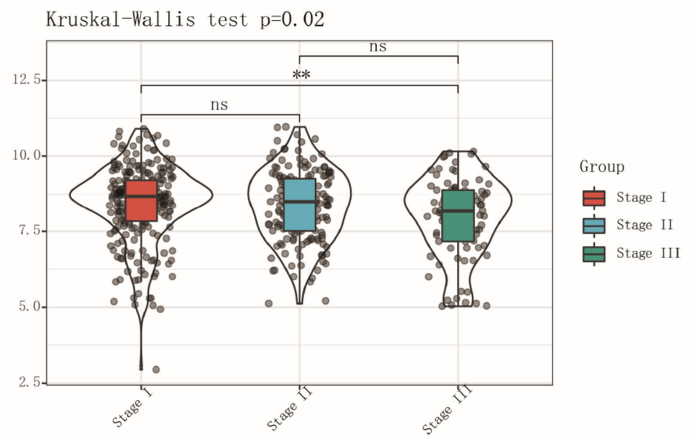

Figure I LARGEI mRNA expression in NSCLC. (A, B) LARGEI expression in lung adenocarcinoma (LUAD) (A) and lung squamous cell carcinoma (LUSC) (B) compared to corresponding adjacent tissues and normal lung tissues. (C-H) LARGEI expression in LUAD (C, E, and $\mathbf{G})$ and LUSC (D, F, and $\mathbf{H})$ with different T stages (C and $\mathbf{D})$, $\mathrm{N}$ stages (E and $\mathbf{F})$, and TNM stages $(\mathbf{G}$ and $\mathbf{H})$. 
Table I Correlations of LARGEI Expression with Clinicopathological Features in Stage I-III NSCLC Patients

\begin{tabular}{|c|c|c|c|}
\hline Clinical Features & Low LARGEI & High LARGE I & $P$-value \\
\hline $\mathbf{N}$ & 489 & 492 & \\
\hline Age (years) & & & 0.002 \\
\hline$<65$ & 208 (43.882\%) & 164 (34.238\%) & \\
\hline$\geq 65$ & $266(56.118 \%)$ & $315(65.762 \%)$ & \\
\hline Gender & & & 0.937 \\
\hline Female & 197 (40.286\%) & 197 (40.04I\%) & \\
\hline Male & 292 (59.7I4\%) & $295(59.959 \%)$ & \\
\hline Smoking history & & & 0.065 \\
\hline Lifelong non-smoker & $43(8.996 \%)$ & $43(8.977 \%)$ & \\
\hline Current smoker & 123 (25.732\%) & $|2|(25.26 \mid \%)$ & \\
\hline Current reformed smoker for $<$ or $=15$ years & $217(45.397 \%)$ & $188(39.248 \%)$ & \\
\hline Current reformed smoker for $>15$ years & 89 (18.619\%) & $124(25.887 \%)$ & \\
\hline Current reformed smoker, duration not specified & $6(1.255 \%)$ & $3(0.626 \%)$ & \\
\hline Histology & & & 0.038 \\
\hline Lung adenocarcinoma & 259 (52.965\%) & 228 (46.34I\%) & \\
\hline Lung squamous cell carcinoma & $230(47.035 \%)$ & $264(53.659 \%)$ & \\
\hline Pathological TNM stages & & & $<0.001$ \\
\hline I & $230(47.035 \%)$ & $293(59.553 \%)$ & \\
\hline II & 155 (31.697\%) & I 34 (27.236\%) & \\
\hline III & 104 (21.268\%) & $65(13.211 \%)$ & \\
\hline Pathological T stages & & & $<0.001$ \\
\hline TI & II 2 (22.904\%) & 167 (33.943\%) & \\
\hline $\mathrm{T} 2$ & 295 (60.327\%) & $256(52.033 \%)$ & \\
\hline T3-4 & $82(16.769 \%)$ & $69(14.024 \%)$ & \\
\hline Pathological N stages & & & $<0.001$ \\
\hline No & 288 (59.627\%) & 347 (7I.399\%) & \\
\hline $\mathrm{NI}$ & II 8 (24.43।\%) & 100 (20.576\%) & \\
\hline N2 & 77 (I5.942\%) & $39(8.025 \%)$ & \\
\hline
\end{tabular}

history, histology, TNM stage, margin, adjuvant chemotherapy, and adjuvant radiotherapy. Association of increasing LARGE1 expression with OS was observed in the subgroup of patients receiving adjuvant chemotherapy but not in other subgroups (Figure 2C). After splitting LARGE1 expression into high and low groups, similar results were obtained by Kaplan-Meier curves and Cox regression analyses (Figure 3A-C; Table 2). And ACT was found to provide more benefit in the high LARGE1 group compared to the low LARGE1 group (Figure 3D and E, and Table 2). We also found a significant interaction between LARGE1 expression and adjuvant chemotherapy when evaluating their effects on OS (Table 2). Furthermore, we classified the patients by combining LARGE1 expression and adjuvant chemotherapy into three groups, ie, non-ACT, low LARGE1/ACT, and high LARGE1/ACT. Compared with patients with non-ACT, HR of low LARGE1/ACT was 0.592 (95\% CI $=0.432-0.813$, $P=0.0012)$, and HR of high LARGE1/ACT was 0.124 (95\% $\mathrm{CI}=0.031-0.505, P=0.0036$ ) (Figure $4 \mathrm{~A}$ and $\mathrm{B}$, and Table 2).

\section{Validation}

The above results suggested high LARGE1 expression might help to identify the patients who would get more benefit from adjuvant chemotherapy in stage I-III NSCLC, so next we validated the results in external cohorts from the GEO database. Datasets GSE42127, GSE14814, GSE29013, and GSE68465 contained resected NSCLC cases treated with ACT or not and provided OS information (Table S1). ACT was found to improve OS in datasets GSE42127 and GSE14814 while decrease OS in datasets GSE29013 and GSE68465, thus validation was only performed in datasets GSE42127 and GSE14814 (Table S2). 
A

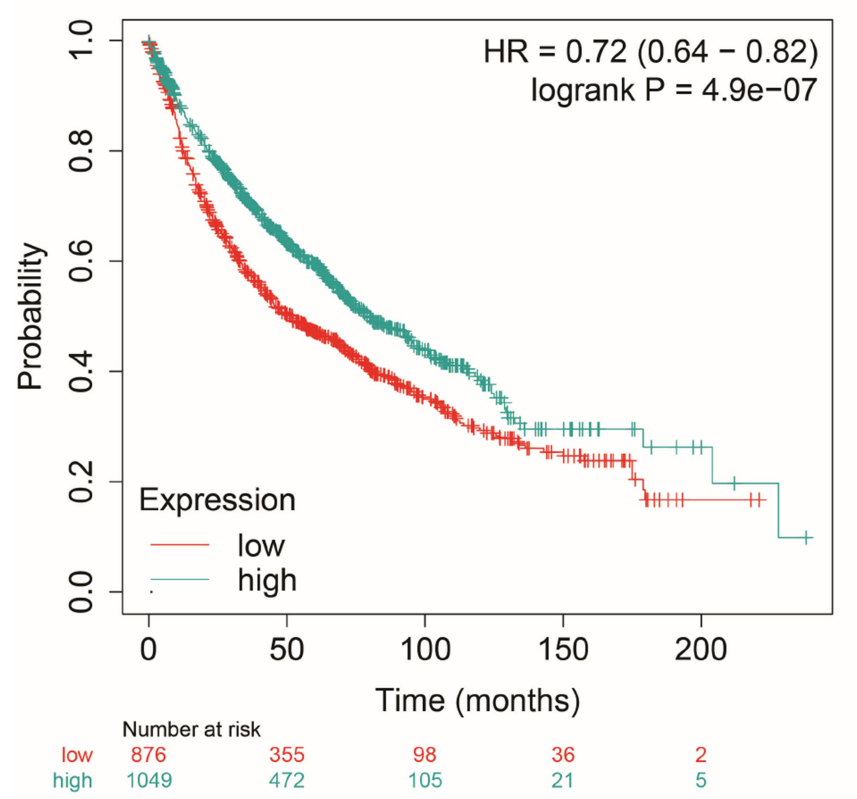

B
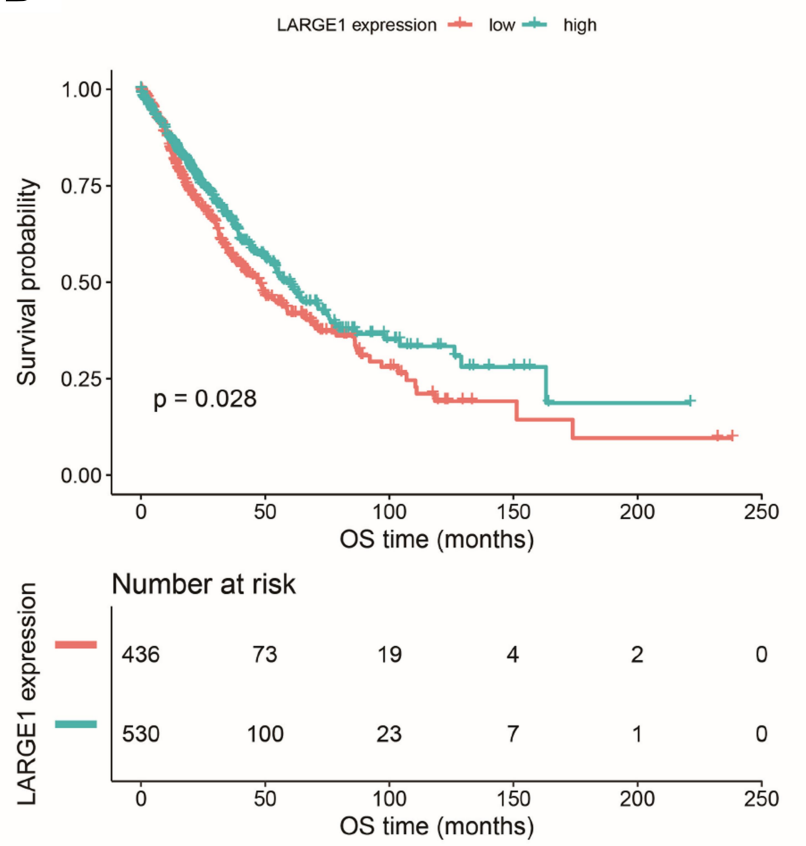

C Subgroup

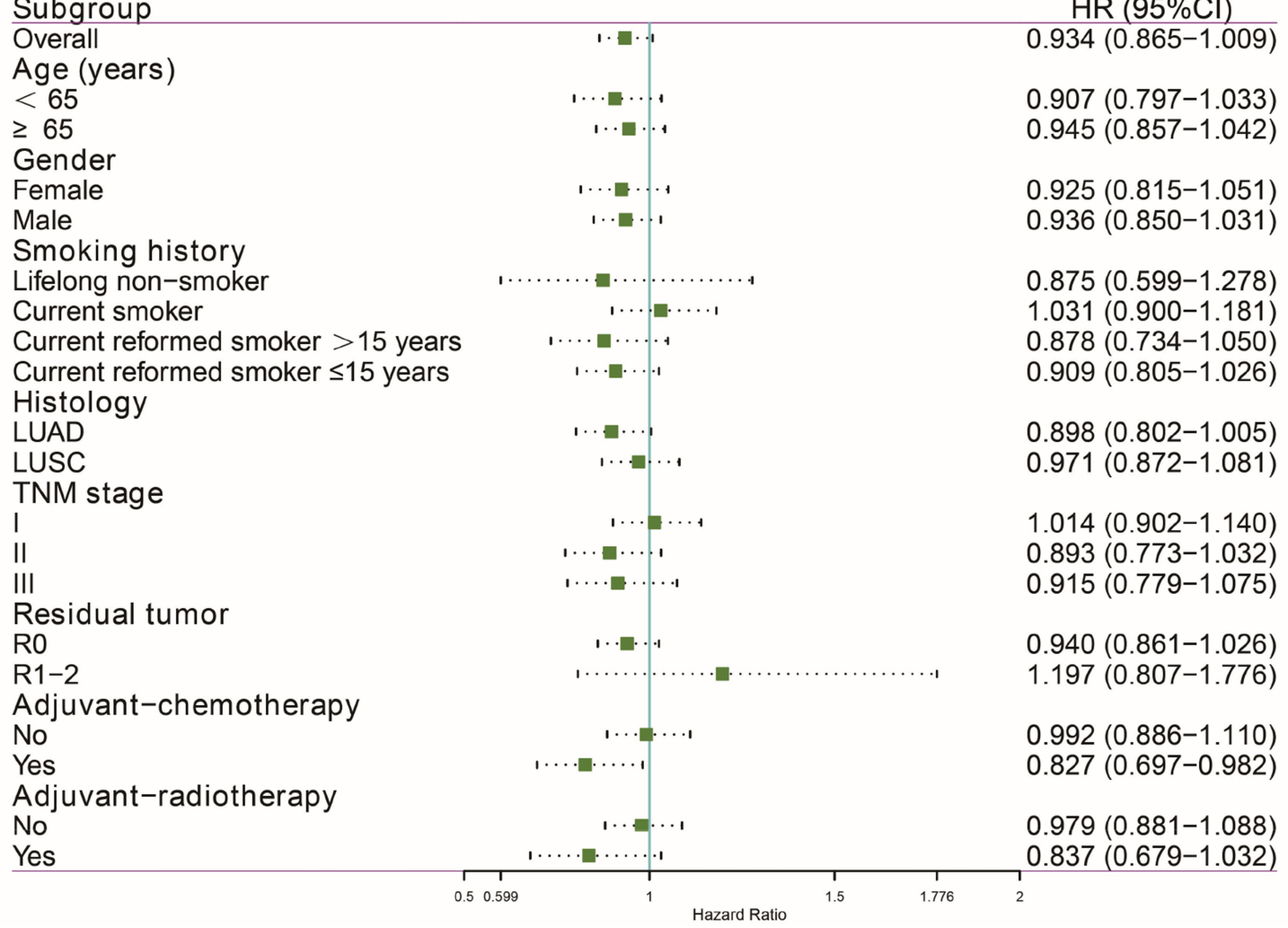

Figure 2 Effects of LARGEI on overall survival (OS) in NSCLC. (A) OS difference between NSCLC patients with high and low LARGEI expression analyzed by the webtool, Kaplan-Meier plotter, using auto select best cutoff value and the JetSet best probe set (215543_s_at). (B) OS difference between TNM I-III NSCLC patients with high and low LARGEI expression from TCGA, analyzed by Kaplan-Meier curve with Log rank test. (C) Forest plot of the hazard ratios (HRs) for the associations of increasing LARGEI expression (serves as a continuous variable) with overall survival (OS) of patients with TNM I-III NSCLC in subgroups stratified by age, gender, smoking history, histology, TNM stage, margin, adjuvant chemotherapy, and adjuvant radiotherapy. 


\section{A}
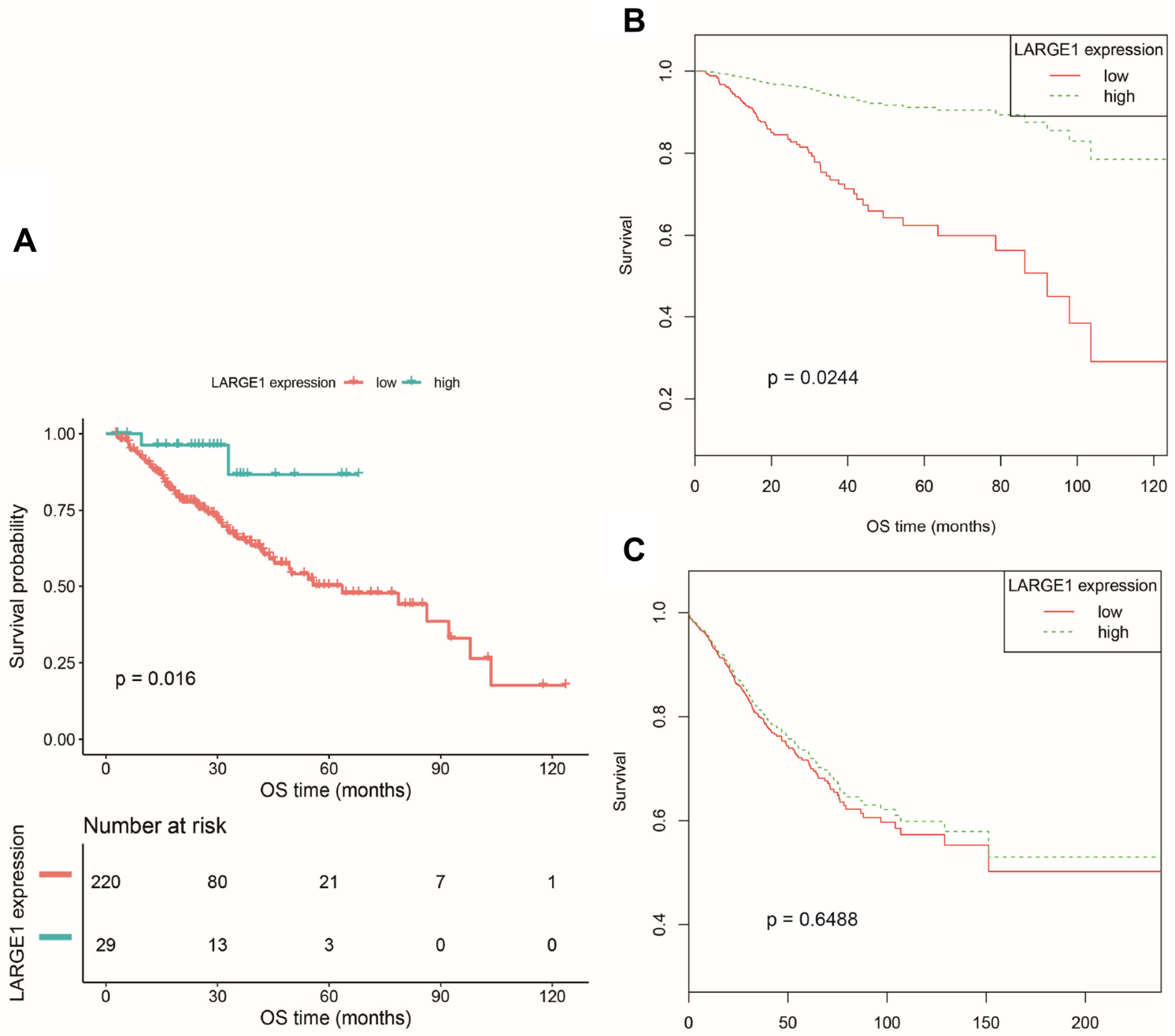

\section{C}

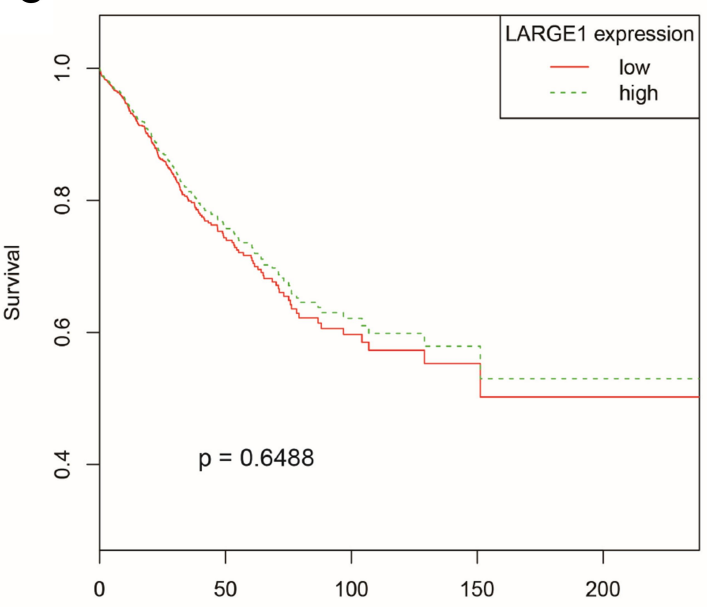

E

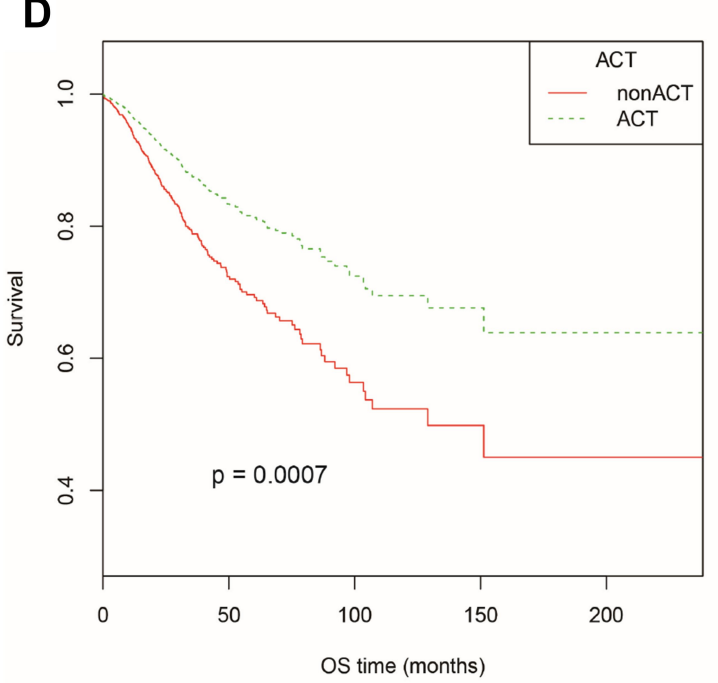

OS time (months)

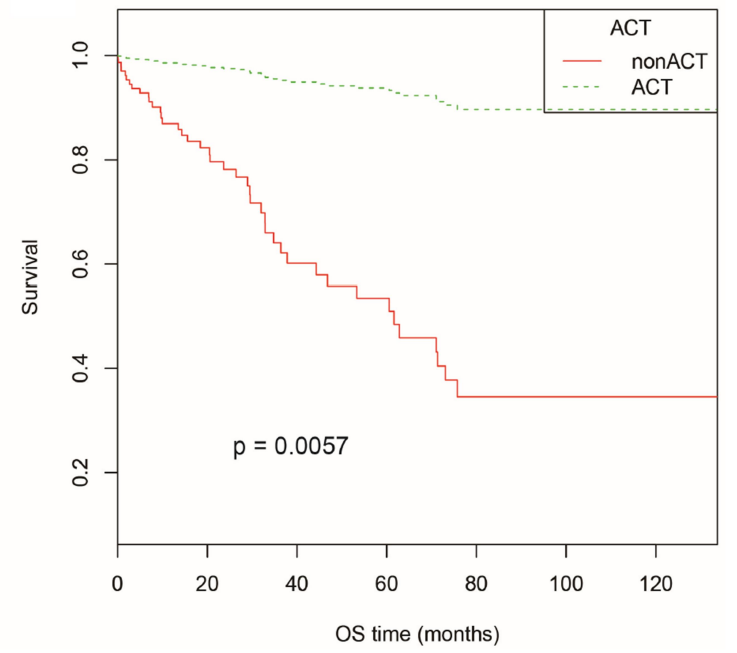

Figure 3 OS difference between TNM I-III NSCLC patients with high and low LARGEI expression split by optimal cutoff value in subgroups stratified by adjuvant chemotherapy treatment (ACT) and between NSCLC patients with and without ACT in subgroups stratified by LARGEI expression, demonstrated by Kaplan-Meier curves. (A) OS difference between NSCLC patients with high and low LARGEI expression in the subgroup with ACT. (B) OS difference between NSCLC patients with high and low LARGEI expression in subgroup of ACT adjusted by the confounding factors. (C) OS difference between NSCLC patients with high and low LARGEI expression in subgroup of non-ACT adjusted by the confounding factors. (D) OS difference between NSCLC patients with and without ACT in the subgroup of low LARGEI expression adjusted by the confounding factors. (E) OS difference between NSCLC patients with and without ACT in the subgroup of high LARGEI expression adjusted by the confounding factors. 
Table 2 Correlations of LARGEI Expression and Chemotherapy with Overall Survival in Different Subgroups of Stage I-III NSCLC Patients at Multivariate Analyses

\begin{tabular}{|c|c|c|c|c|}
\hline \multirow{2}{*}{$\begin{array}{l}\text { Parameters } \\
\text { TCGA }\end{array}$} & \multirow[t]{2}{*}{ HR } & \multicolumn{2}{|c|}{$95 \% \mathrm{Cl}$} & \multirow[t]{2}{*}{ P-value } \\
\hline & & & & \\
\hline LARGEI in patients without ACT & 0.922 & 0.650 & 1.308 & 0.649 \\
\hline LARGEI in patients with ACT & 0.196 & 0.047 & 0.810 & 0.024 \\
\hline ACT in patients with low LARGEI expression & 0.562 & 0.403 & 0.783 & 0.001 \\
\hline$A C T$ in patients with high LARGEI expression & 0.103 & 0.020 & 0.515 & 0.006 \\
\hline Interaction of adjuvant chemotherapy and LARGEI & 0.222 & 0.052 & 0.950 & 0.042 \\
\hline \multicolumn{5}{|l|}{ Combination of ACT and LARGEI expression } \\
\hline Low LARGEI/ACT vs nonACT & 0.592 & 0.432 & 0.813 & 0.001 \\
\hline High LARGEI/ACT vs nonACT & 0.124 & 0.031 & 0.505 & 0.004 \\
\hline \multicolumn{5}{|l|}{ GSE42 I 27} \\
\hline LARGEI in patients without ACT & 0.604 & 0.304 & 1.203 & 0.151 \\
\hline LARGEI in patients with ACT & 0.067 & 0.015 & 0.307 & 0.001 \\
\hline ACT in patients with low LARGEI expression & 1.973 & 0.621 & 6.272 & 0.249 \\
\hline ACT in patients with high LARGEI expression & 0.175 & 0.052 & 0.589 & 0.005 \\
\hline Interaction of adjuvant chemotherapy and LARGEI & 0.152 & 0.032 & 0.721 & 0.018 \\
\hline \multicolumn{5}{|l|}{ Combination of ACT and LARGEI expression } \\
\hline Low LARGEI/ACT vs nonACT & 2.162 & 0.884 & 5.285 & 0.091 \\
\hline High LARGEI/ACT vs nonACT & 0.188 & 0.058 & 0.610 & 0.005 \\
\hline \multicolumn{5}{|l|}{ GSE | $48 \mid 4$} \\
\hline LARGEI in patients without ACT & 1.119 & 0.447 & 2.797 & 0.811 \\
\hline LARGEI in patients with ACT & 0.299 & 0.100 & 0.897 & 0.031 \\
\hline ACT in patients with low LARGEI expression & 1.094 & 0.413 & 2.903 & 0.856 \\
\hline ACT in patients with high LARGEI expression & 0.179 & 0.062 & 0.517 & 0.002 \\
\hline Interaction of adjuvant chemotherapy and LARGEI & 0.278 & 0.072 & 1.078 & 0.064 \\
\hline \multicolumn{5}{|l|}{ Combination of ACT and LARGEI expression } \\
\hline Low LARGEI/ACT vs nonACT & 0.837 & 0.382 & 1.835 & 0.657 \\
\hline High LARGEI/ACT vs nonACT & 0.320 & 0.134 & 0.766 & 0.011 \\
\hline
\end{tabular}

Similar to the results from the TCGA cohort, in both GSE42127 and GSE14814 cohorts, LARGE1 expression was associated with OS in patients with ACT while not in patients without ACT, and ACT was associated with OS in patients with high LARGE1 expression while not in patients with low LARGE1 expression (Figures S1 and $\underline{\mathrm{S}}$; Table 2). The whole cohort of patients was also classified into three groups based on LARGE1 expression and ACT as well as TCGA cohort, compared to patients with nonACT and those with LARGE1/ACT, patients with high LARGE1/ACT were found to be associated with significantly improved OS (Figures S3 and S4; Table 2).

\section{Potential Mechanisms During LARGEI Alteration in Lung Adenocarcinoma}

To elucidate the potential mechanisms during LARGE1 alteration in lung cancer, the Spearman correlations analysis results of more than 20,000 genes with LARGE1 in lung adenocarcinoma were download from TCGA. The genes were ranked by the Spearman's rank $r$ and subjected to Gene Set Enrichment Analysis (GSEA). KEGG pathways, GO biological processes, and hallmarks that were positively or negatively correlated with LARGE1 expression were explored. Figure 5 showed the top 10 negativeand top 10 positive-associated gene sets against KEGG (Figure 5A), HALLMARK (Figure 5B), and GO biological processes (Figure $5 \mathrm{C}$ ) databases, respectively. KEGG Cell cycle pathway (Figure 6A), HALLMARK G2/M checkpoint (Figure 6B), and GO cell cycle G2/M phase transition (Figure 6C) were all negatively associated with LARGE1 expression, indicating LARGE1 might improve patients' outcomes via partly downregulating cell cycle in lung adenocarcinoma. The result was further validated by examining the association of LARGE1 expression with cell cycle pathway score, which was calculated by summing cell cycle-related proteins expression (Figure 6D). 

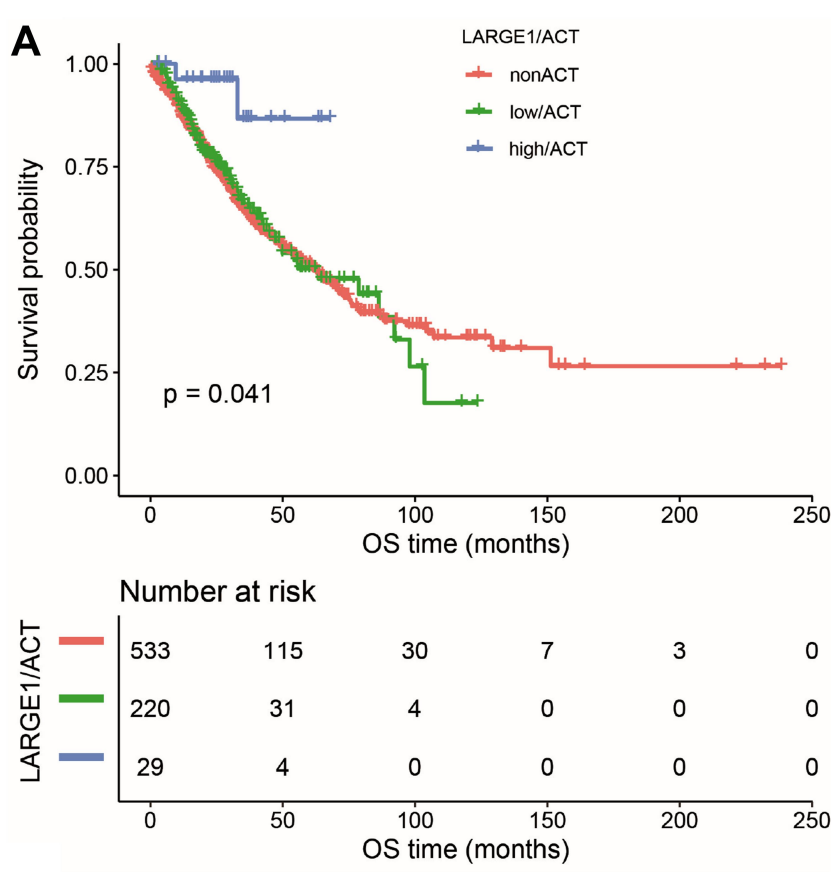

B

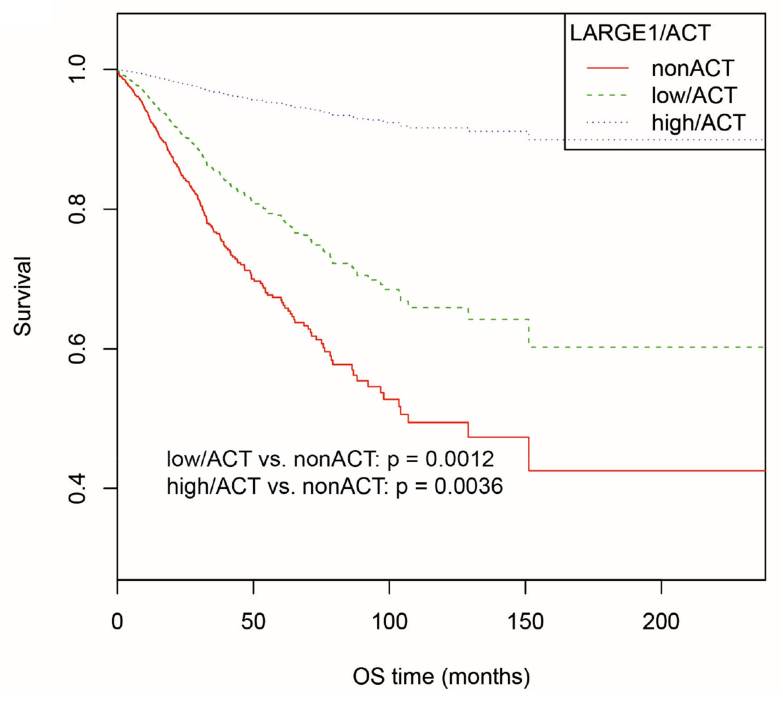

Figure 4 OS difference in TNM I-III NSCLC patients stratified by combining LARGEI expression and adjuvant chemotherapy (ACT), ie, non-ACT, low LARGEI/ACT, and high LARGEI/ACT. (A and B) LARGEI expression was split into high and low groups by optimal cutoff value; OS difference of patients with non-ACT, low LARGEI/ACT, and high LARGEI/ACT was analyzed by Kaplan-Meier curve (A), which was also analyzed by adjusting the confounding factors (B).

\section{Discussion}

$\alpha$-Dystroglycan functions as an extracellular matrix (ECM) receptor $^{29}$ for several LG domain-containing basement membrane proteins via a unique heteropolysaccharide [GlcA-beta1,3-Xyl-alpha1,3- $]_{\mathrm{n}}$ called matriglycan, including laminin, ${ }^{30-32}$ perlecan, ${ }^{33}$ agrin, ${ }^{34}$ and Slit. ${ }^{35} \alpha$-DG has been implicated in several cell functions (ie, growth control, differentiation, shape change and movement) which are all relevant in the process of tumor development and metastasis. ${ }^{36,37}$ Expression or glycosylation of $\alpha$-DG has been identified to be lost or reduced in a variety of human cancer cell lines ${ }^{17,38}$ and different cancers including rhabdomyosarcoma ${ }^{18}$ gliomas, ${ }^{39}$ breast,${ }^{40,41}$ prostate, ${ }^{42}$ colon, ${ }^{41,43}$ cervical, ${ }^{44}$ vulvar, ${ }^{44}$ gastric,${ }^{45}$ tongue, ${ }^{46}$ and pancreatic cancers, ${ }^{47}$ oral squamous cell carcinoma, ${ }^{48}$ and renal cell carcinoma. ${ }^{49}$ Such reduction or loss of $\alpha$-DG seems to correlate with the biologically invasive character of primary tumors $^{41,44,46,47,49-51}$ and associated with poor outcomes. ${ }^{41,43,45,47,49,51}$ LARGE1 is important for $\alpha$-DG glycosylation by adding the laminin-binding repeating units of 3GlcA-1-3Xyl-1 onto $\alpha-\mathrm{DG}^{16}$ and significant association of LARGE1 downregulation with abnormal $\alpha$-DG glycosylation in cancer cells has been observed. ${ }^{17,18}$ In the present study, we, for the first time, have reported that LARGE1 mRNA expression was downregulated in lung cancer tissues compared with adjacent tissues and normal lung tissues and in patients with advanced stages compared with early stages via analyzing the large dataset from the TCGA database. And there was a trend of significant association between LARGE1 downregulation with poor overall survival in stage I-III patients in overall and LARGE1 downregulation was significantly associated with poor overall survival in stage I-III patients receiving ACT.

ACT is the standard care for patients with NSCLC after complete resection, unfortunately, only a few of the patients get to benefit from ACT due to primary and acquired drug resistance. ${ }^{14,15}$ Therefore, it is critical to develop predictive biomarkers to identify the patients who will benefit from ACT and who will not benefit from ACT to avoid unnecessary toxicity and the delay of further treatment. Previously, low expression of $\mathrm{ERCC1}^{52}$ and high expression of TUBB $^{53}$ were shown to be predictive of benefit from ACT in NSCLC patients from a large cohort or clinical trial. However, large cross-validation studies suggested that attempts to validate ERCC1 or TUBB3 as predictive biomarkers fell short. ${ }^{54,55}$ Similar results were derived for validating other single biomarkers including p53, RRM1, and 2 27. ${ }^{56-58}$ Here, we found high LARGE1 mRNA expression can be used to identify the patients who would benefit from ACT, which was also validated in external 
A

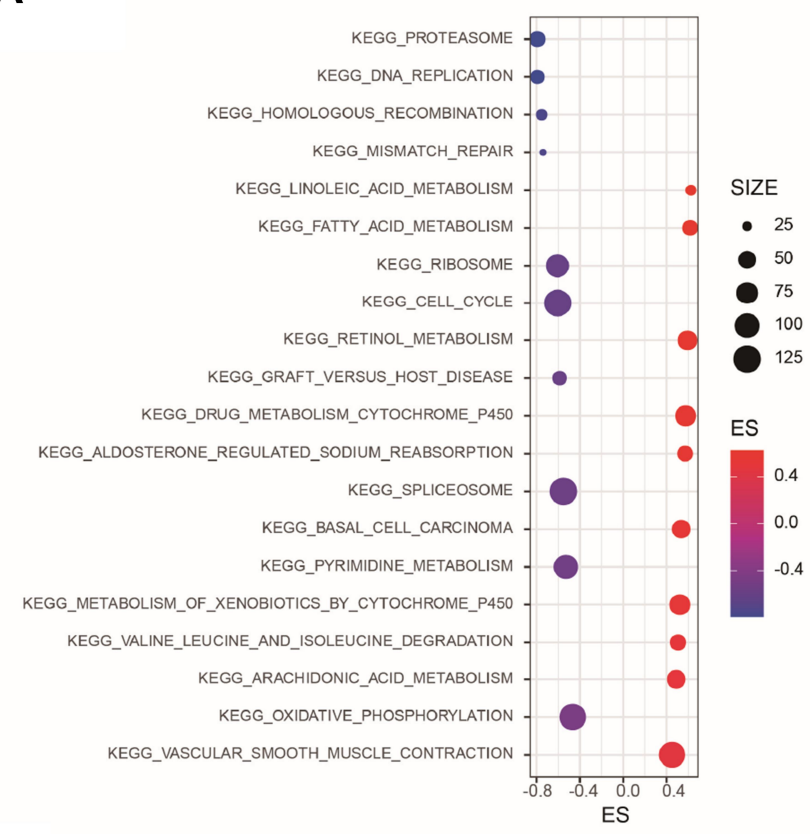

B

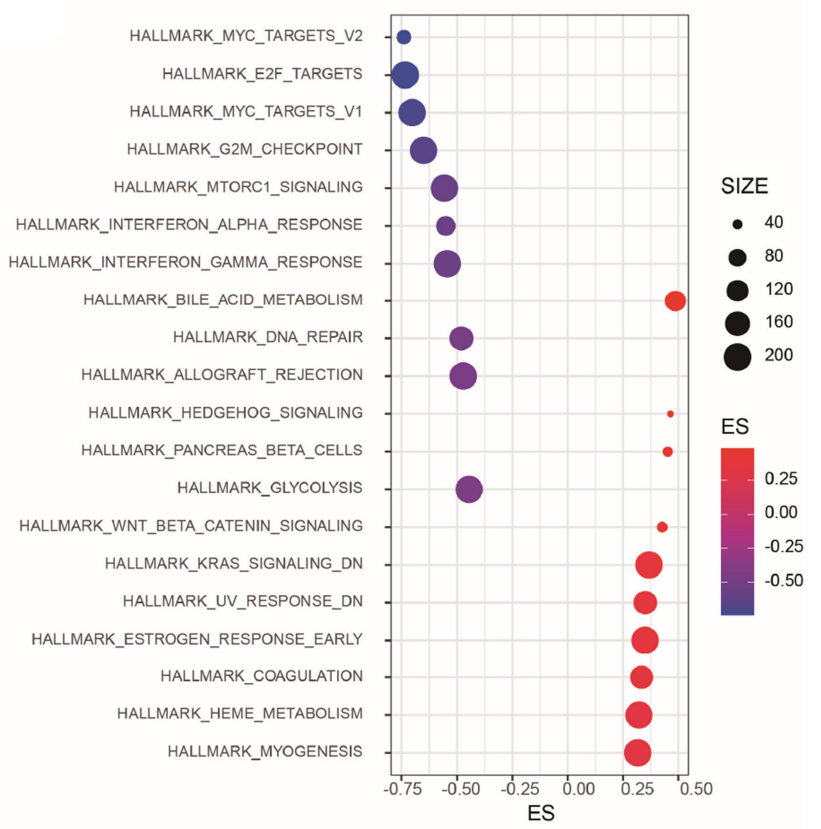

C

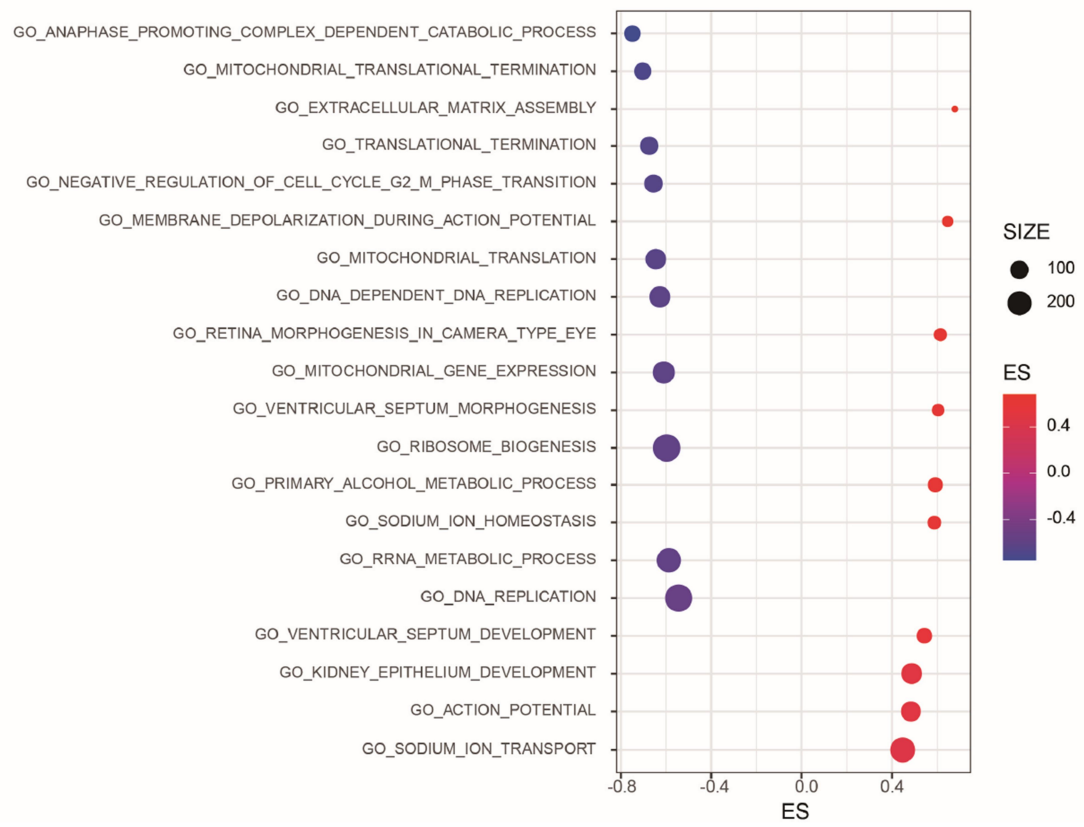

Figure 5 Gene Set Enrichment Analysis (GSEA) of LARGEI co-expressed genes in lung adenocarcinoma (LUAD). Genes were ranked by Spearman's rank rho association with LARGEI expression were subjected to GSEA with KEGG pathways, HALLMARKS, and GO biological processes as reference databases. (A) The top I0 negative and top 10 positive KEGG pathways associated with LARGEI expression. (B) The top 10 negative and top 10 positive HALLMARKS associated with LARGEI expression. (C) The top 10 negative and top 10 positive GO biological processes associated with LARGEI expression.

cohorts, although this should be validated in more and larger multi-center studies.

LARGE1 is essential for $\alpha$-DG glycosylation, which mediates the interaction between cells and the ECM and may play critical roles in the development and progression of many cancers by modulating cell growth, differentiation, shape change, and movement. ${ }^{36,37,59}$ In our study, we performed GSEA and found cell cycle regulation during LARGE1 alteration might be involved in carcinogenesis of lung adenocarcinoma, which might also be associated with ACT sensitivity. The potential mechanisms of LARGE1 downregulation in lung cancer were also unknown. Zhang 
A

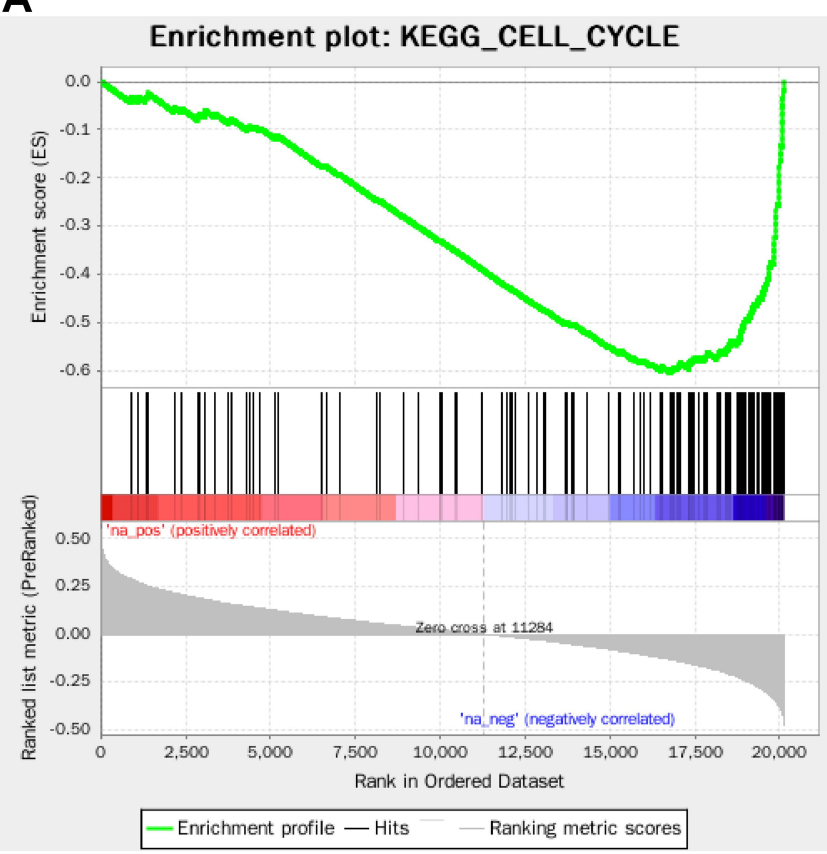

C
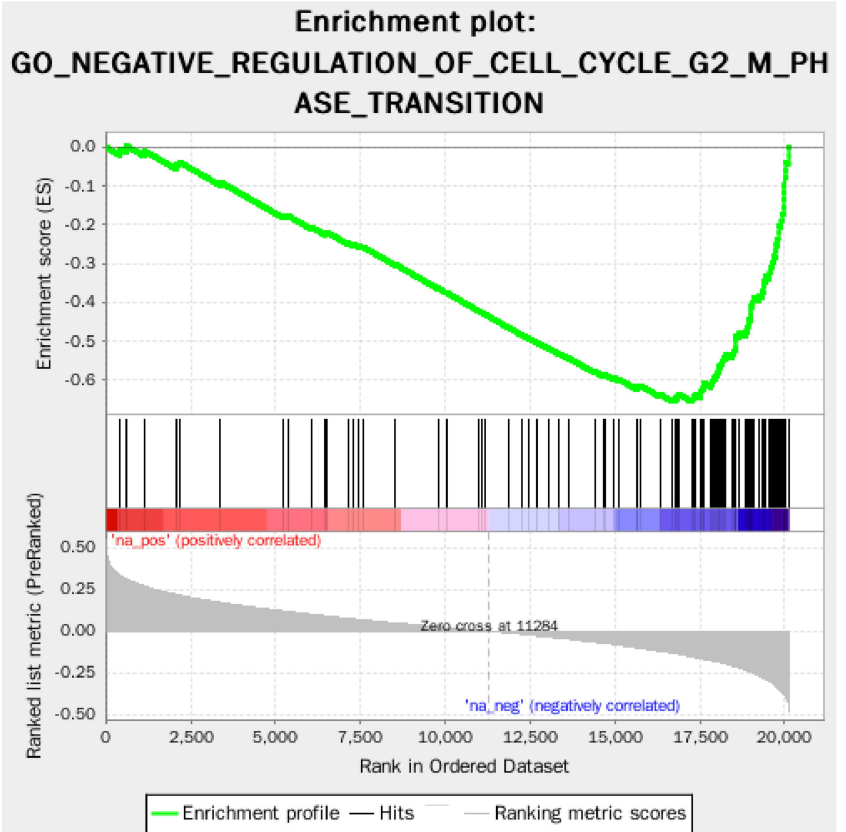

B
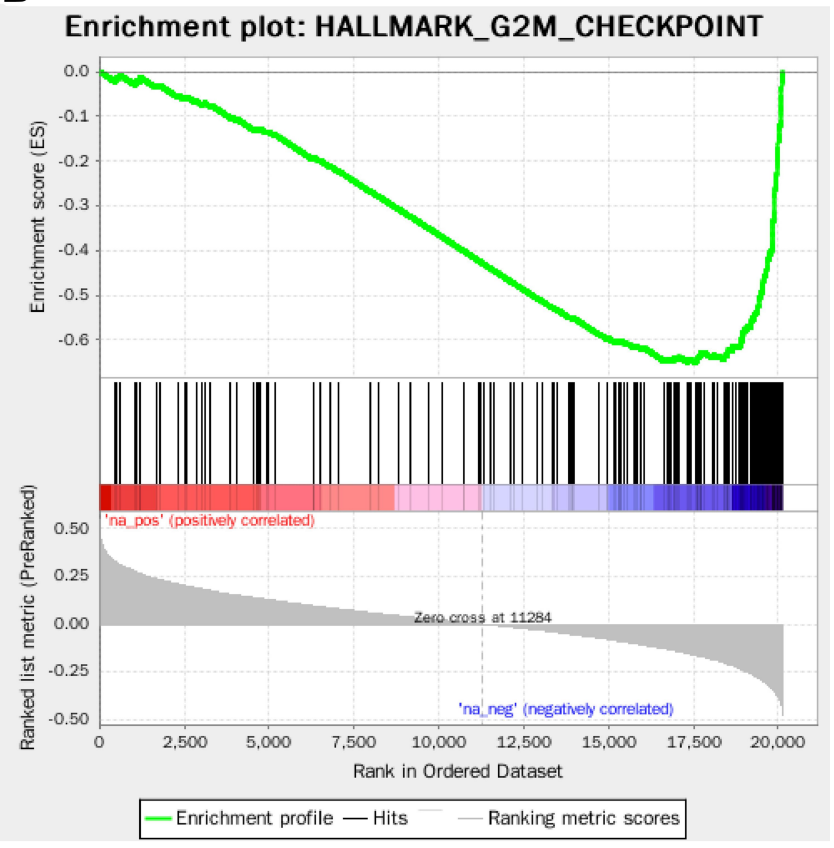

D
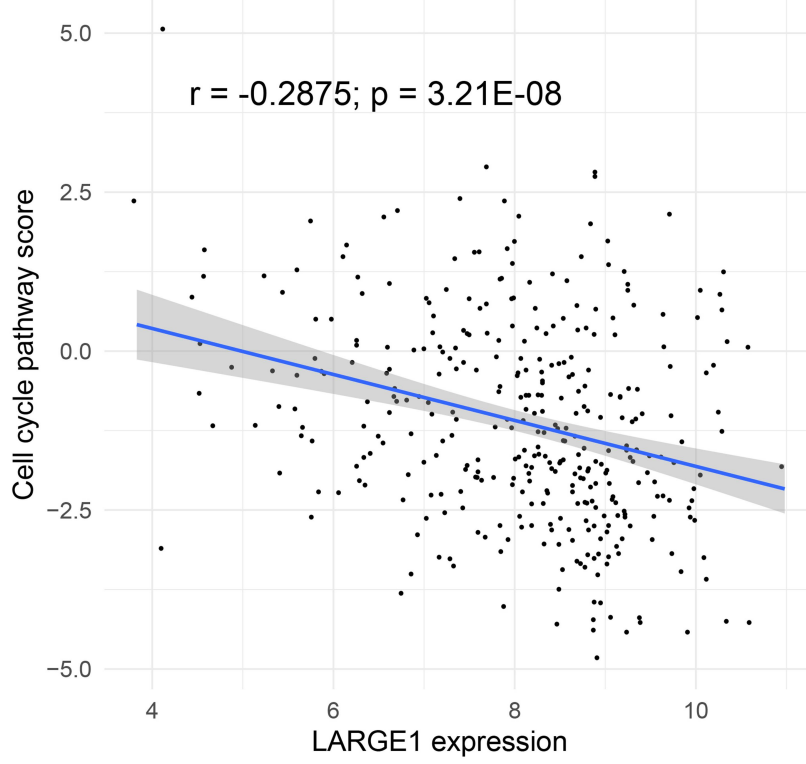

Figure 6 LARGEI expression was negatively associated with cell cycle in lung adenocarcinoma (LUAD). (A-C) KEGG Cell cycle pathway (A), HALLMARK G2/M checkpoint (B), and GO cell cycle G2/M phase transition (C) were all negatively associated with LARGEI expression. (D) The association of LARGEI expression with cell cycle pathway score, which was calculated by summing cell cycle-related proteins expression.

et al reported that reduced LARGE1 expression was associated with its promoter hypermethylation in tongue cancer. $^{46}$ In lung cancer, we also identified the negative and significant association between LARGE1 mRNA expression and the methylation of the $\mathrm{CpG}$ islands at its promoter (data not shown). More in vitro and animal experiments should be performed to validate our results.

\section{Conclusions}

LARGE1 mRNA expression was aberrantly downregulated in NSCLC and especially in cancers with advanced stages. High LARGE1 mRNA expression was associated with favorable OS in NSLCLC patients undergoing adjuvant chemotherapy rather than in patients without ACT and improved OS after ACT was also found in patients with high LARGE1 
than those with low LARGE1. External cohorts confirmed these results, indicating that high LARGE expression could be used to identify the NSCLC patients who benefited from adjuvant chemotherapy.

\section{Acknowledgment}

This study was supported by the subjects from the Natural Science Foundation of China (NSFC81601849), Zhejiang Provincial Medicine and Health Technology Project (2019RC217), Wenzhou Science and Technology Bureau (Y20180109, Y20180254).

\section{Disclosure}

The authors report no conflicts of interest in this work.

\section{References}

1. Siegel RL, Miller KD, Jemal A. Cancer statistics, 2020. CA Cancer J Clin. 2020;70(1):425.

2. Travis WD. Pathology of lung cancer. Clin Chest Med. 2011;32 (4):669-692. doi:10.1016/j.ccm.2011.08.005

3. Torre LA, Siegel RL, Jemal A. Lung cancer statistics. Adv Exp Med Biol. 2016;893:893. doi:10.1007/978-3-319-24223-1_1

4. Xue C, Hu Z, Jiang W, et al. National survey of the medical treatment status for non-small cell lung cancer (NSCLC) in China. Lung Cancer. 2012;77(2):371-375. doi:10.1016/j.lungcan.2012.04.014

5. Hung -J-J, Jeng W-J, Hsu W-H, Huang B-S, Wu Y-C. Time trends of overall survival and survival after recurrence in completely resected stage I non-small cell lung cancer. $J$ Thorac Oncol. 2012;7 (2):397-405. doi:10.1097/JTO.0b013e31823b564a

6. Su S, Scott WJ, Allen MS, et al. Patterns of survival and recurrence after surgical treatment of early stage non-small cell lung carcinoma in the ACOSOG Z0030 (ALLIANCE) trial. $J$ Thorac Cardiovasc Surg. 2014;147(2):2. doi:10.1016/j.jtcvs.2013.10.001

7. Chen W, Zheng R, Zhang S, Zhao P, Zeng H, Zou X. Report of cancer incidence and mortality in China, 2010. Ann Transl Med. 2014;2(7):61. doi:10.3978/j.issn.2305-5839.2014.04.05

8. Galluzzi L, Buqué A, Kepp O, Zitvogel L, Kroemer G. Immunological effects of conventional chemotherapy and targeted anticancer agents. Cancer Cell. 2015;28(6):690-714. doi:10.1016/j.ccell.2015.10.012

9. Arriagada R, Bergman B, Dunant A, Le Chevalier T. Cisplatin-based adjuvant chemotherapy in patients with completely resected non-small-cell lung cancer. $N$ Engl J Med. 2004;350(4):351-360.

10. Waller D, Peake MD, Stephens RJ, et al. Chemotherapy for patients with non-small cell lung cancer: the surgical setting of the Big Lung Trial. Eur J Cardiothorac Surg. 2004;26(1):173-182. doi:10.1016/j. ejcts.2004.03.041

11. Winton T, Livingston R, Johnson D, et al. Vinorelbine plus cisplatin vs. observation in resected non-small-cell lung cancer. $N$ Engl J Med. 2005;352(25):2589-2597. doi:10.1056/NEJMoa043623

12. Douillard J-Y, Rosell R, De Lena M, et al. Adjuvant vinorelbine plus cisplatin versus observation in patients with completely resected stage IB-IIIA non-small-cell lung cancer (Adjuvant Navelbine International Trialist Association [ANITA]): a randomised controlled trial. Lancet Oncol. 2006;7(9):719-727. doi:10.1016/S1470-2045(06)70804-X

13. Strauss GM, Herndon JE, Maddaus MA, et al. Adjuvant paclitaxel plus carboplatin compared with observation in stage IB non-smallcell lung cancer: CALGB 9633 with the Cancer and Leukemia Group B, Radiation Therapy Oncology Group, and North Central Cancer Treatment Group Study Groups. J Clin Oncol. 2008;26 (31):5043-5051. doi:10.1200/JCO.2008.16.4855
14. Pignon J-P, Tribodet H, Scagliotti GV, et al. Lung adjuvant cisplatin evaluation: a pooled analysis by the LACE Collaborative Group. J Clin Oncol. 2008;26(21):3552-3559. doi:10.1200/ JCO.2007.13.9030

15. Kelland L. The resurgence of platinum-based cancer chemotherapy. Nat Rev Cancer. 2007;7(8):573-584. doi:10.1038/nrc2167

16. Inamori K, Hara Y, Willer T, et al. Xylosyl- and glucuronyltransferase functions of LARGE in $\alpha$-dystroglycan modification are conserved in LARGE2. Glycobiology. 2013;23(3):295-302. doi:10.1093/glycob/ cws 152

17. de Bernabé DB-V, Inamori K-I, Yoshida-Moriguchi T, et al. Loss of $\alpha$-dystroglycan laminin binding in epithelium-derived cancers is caused by silencing of LARGE. J Biol Chem. 2009;284 (17):11279-11284. doi:10.1074/jbc.C900007200

18. Beltrán D, Anderson ME, Bharathy N, et al. Exogenous expression of the glycosyltransferase LARGE1 restores $\alpha$-dystroglycan matriglycan and laminin binding in rhabdomyosarcoma. Skeletal Muscle. 2019;9 (1):11. doi:10.1186/s13395-019-0195-0

19. Goldman MJ, Craft B, Hastie M, et al. Visualizing and interpreting cancer genomics data via the Xena platform. Nat Biotechnol. 2020;38 (6):675-678. doi:10.1038/s41587-020-0546-8

20. Győrffy B, Surowiak P, Budczies J, Lánczky A, Chellappan SP. Online survival analysis software to assess the prognostic value of biomarkers using transcriptomic data in non-small-cell lung cancer. PLoS One. 2013;8(12):e82241. doi:10.1371/journal.pone.0082241

21. Tang H, Xiao G, Behrens C, et al. A 12-Gene Set Predicts Survival Benefits from Adjuvant Chemotherapy in Non-Small Cell Lung Cancer Patients. Clin Cancer Res. 2013;19(6):1577-1586. doi:10.1158/1078-0432.CCR-12-2321

22. Zhu C-Q, Ding K, Strumpf D, Zhu CQ, Ding K, Strumpf D, et al. Prognostic and Predictive Gene Signature for Adjuvant Chemotherapy in Resected Non-Small-Cell Lung Cancer. $J$ Clin Oncol. 2010;28(29):4417-4424. doi:10.1200/JCO.2009.26.4325

23. Lung A, Shedden K, Taylor JM, et al. Gene expression-based survival prediction in lung adenocarcinoma: a multi-site, blinded validation study. Nat Med. 2008;14(8):822-827.

24. Cerami E, Gao J, Dogrusoz U, et al. The cBio Cancer Genomics Portal: an open platform for exploring multidimensional cancer genomics data: figure 1. Cancer Discov. 2012;2(5):401. doi:10.1158/21598290.CD-12-0095

25. Gao J, Aksoy BA, Dogrusoz U, et al. Integrative analysis of complex cancer genomics and clinical profiles using the cBioPortal. Sci Signal. 2013;6(269):pl1. doi:10.1126/scisignal.2004088

26. Subramanian A, Tamayo P, Mootha VK, et al. Gene set enrichment analysis: A knowledge-based approach for interpreting genome-wide expression profiles. Proc Natl Acad Sci U S A. 2005;102(43):15545. doi:10.1073/pnas.0506580102

27. Mootha VK, Lindgren CM, Eriksson K-F, et al. PGC-1 $\alpha$-responsive genes involved in oxidative phosphorylation are coordinately downregulated in human diabetes. Nat Genet. 2003;34(3):267-273. doi: $10.1038 / \mathrm{ng} 1180$

28. Akbani R, Ng PKS, Werner HMJ, et al. A pan-cancer proteomic perspective on The Cancer Genome Atlas. Nat Commun. 2014;5 (1):3887. doi:10.1038/ncomms4887

29. Barresi R. Dystroglycan: from biosynthesis to pathogenesis of human disease. J Cell Sci. 2006;119(2):199-207. doi:10.1242/jcs.02814

30. Yamada H, Denzer AJ, Hori H, et al. Dystroglycan is a dual receptor for agrin and laminin-2 in Schwann cell membrane. J Biol Chem. 1996;271(38):23418-23423. doi:10.1074/jbc.271.38.23418

31. Kanagawa M, Saito F, Kunz S, et al. Molecular recognition by LARGE is essential for expression of functional dystroglycan. Cell. 2004;117(7):953-964. doi:10.1016/j.cell.2004.06.003

32. Kunz S, Sevilla N, McGavern DB, Campbell KP, Oldstone MBA. Molecular analysis of the interaction of LCMV with its cellular receptor $\alpha$-dystroglycan. $J$ Cell Biol. 2001;155(2):301-310. doi: $10.1083 /$ jcb. 200104103 
33. Gee SH, Montanaro F, Lindenbaum MH, Carbonetto S. Dystroglycan- $\alpha$, a dystrophin-associated glycoprotein, is a functional agrin receptor. Cell. 1994;77(5):675-686. doi:10.1016/ 0092-8674(94)90052-3

34. Talts JF, Andac Z, Göhring W, Brancaccio A, Timpl R. Binding of the $\mathrm{G}$ domains of laminin $\alpha 1$ and $\alpha 2$ chains and perlecan to heparin, sulfatides, $\alpha$-dystroglycan and several extracellular matrix proteins. EMBO J. 1999;18(4):863-870. doi:10.1093/emboj/18.4.863

35. Wright KM, Lyon KA, Leung H, Leahy DJ, Ma L, Ginty DD Dystroglycan organizes axon guidance cue localization and axonal pathfinding. Neuron. 2012;76(5):931-944. doi:10.1016/j. neuron.2012.10.009

36. Sgambato A, Brancaccio A. The dystroglycan complex: from biology to cancer. $J$ Cell Physiol. 2005;205(2):163-169. doi:10.1002/ jcp. 20411

37. Sgambato A, Di Salvatore MA, De Paola B, et al. Analysis of dystroglycan regulation and functions in mouse mammary epithelial cells and implications for mammary tumorigenesis. J Cell Physiol. 2006;207(2):520-529. doi:10.1002/jcp.20600

38. Losasso C, Di Tommaso F, Sgambato A, et al. Anomalous dystroglycan in carcinoma cell lines. FEBS Lett. 2000;484(3):194-198. doi:10.1016/S0014-5793(00)02157-8

39. Calogero A, Pavoni E, Gramaglia T, et al. Altered expression of alpha-dystroglycan subunit in human gliomas. Cancer Biol Ther. 2006;5(4):441-448. doi:10.4161/cbt.5.4.2546

40. Sgambato A, Camerini A, Faraglia B, et al. Increased expression of dystroglycan inhibits the growth and tumorigenicity of human mammary epithelial cells. Cancer Biol Ther. 2004;3(10):967-975. doi:10.4161/cbt.3.10.1132

41. Sgambato A, Migaldi M, Montanari M, et al. Dystroglycan expression is frequently reduced in human breast and colon cancers and is associated with tumor progression. Am J Pathol. 2003;162 (3):849-860. doi:10.1016/S0002-9440(10)63881-3

42. Sgambato A, De Paola B, Migaldi M, et al. Dystroglycan expression is reduced during prostate tumorigenesis and is regulated by androgens in prostate cancer cells. J Cell Physiol. 2007;213(2):528-539. doi:10.1002/jcp. 21130

43. Coco C, Zannoni GF, Caredda E, et al. Increased expression of CD133 and reduced dystroglycan expression are strong predictors of poor outcome in colon cancer patients. J Exp Clin Cancer Res. 2012;31(1):71. doi:10.1186/1756-9966-31-71

44. Sgambato A, Tarquini E, Resci F, et al. Aberrant expression of $\alpha$ dystroglycan in cervical and vulvar cancer. Gynecol Oncol. 2006;103 (2):397-404. doi:10.1016/j.ygyno.2006.03.059

45. Moon YW, Rha SY, Zhang X, et al. Increments of $\alpha$-dystroglycan expression in liver metastasis correlate with poor survival in gastric cancer. J Surg Oncol. 2009;100(6):459-465. doi:10.1002/jso.21347

46. Zhang H-Z, Xia X-Y, Zhu F, Shen H, Song K, Shang Z-J. Correlation of deregulated like-acetylglucosaminyl transferase and aberrant $\alpha$ dystroglycan expression with human tongue cancer metastasis J Oral Maxillofac Surg. 2014;72(6):1106-1118. doi:10.1016/j. joms.2013.12.031
47. Jiang X, Rieder S, Giese NA, Friess H, Michalski CW, Kleeff KJ. Reduced $\alpha$-dystroglycan expression correlates with shortened patient survival in pancreatic cancer. J Surg Res. 2011;171(1):120-126. doi:10.1016/j.jss.2009.11.730

48. Jing J, Lien CF, Sharma S, Rice J, Brennan PA, Górecki DC. Aberrant expression, processing and degradation of dystroglycan in squamous cell carcinomas. Eur J Cancer. 2004;40(14):2143-2151. doi:10.1016/j.ejca.2004.05.018

49. Sgambato A, Camerini A, Amoroso D, et al. Expression of dystroglycan correlates with tumor grade and predicts survival in renal cell carcinoma. Cancer Biol Ther. 2007;6(12):1840-1846. doi:10.4161/ cbt.6.12.4983

50. Henry MD, Cohen MB, Campbell KP. Reduced expression of dystroglycan in breast and prostate cancer. Hum Pathol. 2001;32 (8):791-795. doi:10.1053/hupa.2001.26468

51. Shen JG, Xu CY, Li X, et al. Dystroglycan is associated with tumor progression and patient survival in gastric cancer. Pathol Oncol Res. 2012;18(1):79-84. doi:10.1007/s12253-011-9419-2

52. Olaussen KA, Dunant A, Fouret P, et al. DNA repair by ERCC1 in non-small-cell lung cancer and cisplatin-based adjuvant chemotherapy. $N$ Engl J Med. 2006;355(10):983-991. doi:10.1056/NEJM oa060570

53. Sève P, Lai R, Ding K, Sève P, Lai R, Ding K, et al. Class III $\beta$ tubulin expression and benefit from adjuvant cisplatin/vinorelbine chemotherapy in operable non-small cell lung cancer: analysis of NCIC JBR.10. Clin Cancer Res. 2007;13(3):994-999. doi:10.1158/ 1078-0432.CCR-06-1503

54. Reiman T, Lai R, Veillard AS, et al. Cross-validation study of class III beta-tubulin as a predictive marker for benefit from adjuvant chemotherapy in resected non-small-cell lung cancer: analysis of four randomized trials. Ann Oncol. 2012;23(1):86-93. doi:10.1093/ annonc/mdr033

55. Friboulet L, Olaussen KA, Pignon J-P, et al. ERCC1 isoform expression and DNA repair in non-small-cell lung cancer. $N$ Engl J Med. 2013;368(12):1101-1110. doi:10.1056/NEJMoa1214271

56. Olaussen KA, Postel-Vinay S. Predictors of chemotherapy efficacy in non-small-cell lung cancer: a challenging landscape. Ann Oncol. 2016;27(11):2004-2016. doi:10.1093/annonc/mdw321

57. Wallerek S, Sørensen JB. Biomarkers for efficacy of adjuvant chemotherapy following complete resection in NSCLC stages I-IIIA. Eur Respir Rev. 2015;24(136):340-355. doi:10.1183/16000617. 00005814

58. Seymour L, Le Teuff G, Brambilla E, et al. LACE-Bio: validation of predictive and/or prognostic immunohistochemistry/histochemistrybased biomarkers in resected non-small-cell lung cancer. Clin Lung Cancer. 2019;20(2):2. doi:10.1016/j.cllc.2018.10.001

59. Petersen OW, Rønnov-Jessen L, Howlett AR, Bissell MJ. Interaction with basement membrane serves to rapidly distinguish growth and differentiation pattern of normal and malignant human breast epithelial cells. Proc Natl Acad Sci U S A. 1992;89(19):9064-9068. doi:10.1073/pnas.89.19.9064

\section{Publish your work in this journal}

Pharmacogenomics and Personalized Medicine is an international, peer-reviewed, open access journal characterizing the influence of genotype on pharmacology leading to the development of personalized treatment programs and individualized drug selection for improved safety, efficacy and sustainability. This journal is indexed on the American Chemical Society's Chemical Abstracts Service (CAS). The manuscript management system is completely online and includes a very quick and fair peer-review system, which is all easy to use. Visit http://www.dovepress.com/testimonials.php to read real quotes from published authors. 